\title{
Moral Hazard in Repeated Procurement of Services*
}

\author{
Patricia Esteve-González ${ }^{\dagger}$
}

\begin{abstract}
This paper analyses repeated procurement of services as a two period model with a potential repeated agency relationship. In the first period, there is an incumbent who provides a service. In the second period, there is a contest stage in which the principal selects the next service provider. The agents' effort is non-contractible and the contest stage is the mechanism to mitigate potential moral hazard problems. The principal takes account of the past service effort in the contest stage by choosing the weight of past effort and the degree of substitutability between past and current efforts. The results show that, when the principal does not value contest effort, considering past effort as the relevant effort in the contest is optimal. When the principal values contest effort and effort cost increases, decreasing substitutability between efforts is optimal.
\end{abstract}

JEL classification: C72; D72; D82

Key words: Biased contest; Moral Hazard; Incentives.

*I am indebted to Matthias Dahm, Bernd Theilen and anonymous referees for their valuable comments and suggestions. I thank José Alcalde, Andrew Clausen, Maria Cubel, Kohei Kawamura, Carolina Manzano, María Montero, Antonio Quesada, Santiago Sánchez-Pages, all members of GRODE (Universitat Rovira i Virgili), and conference participants at ASSET (University of the Basque Country), SAEe (Universidad de Vigo), REES (Universidad de Salamanca), EBIM (Universität Bielefeld) and Edinburgh-Barcelona PhD meeting (Universitat de Barcelona) for their helpful comments. I gratefully acknowledge the financial support from the Spanish Ministry of Science and Innovation (MEC project No. ECO2010-19733).

${ }^{\dagger}$ Departament d'Economia and CREIP, Universitat Rovira i Virgili, Av. de la Universitat 1, 43204 Reus, Spain. E-mail: patricia.esteve@urv.cat 


\section{Introduction}

Analysing service procurement procedures is relevant for many public and private situations because of the economic importance of the services sector. In 2013, the services sector represented $70 \%$ of the world's GDP (World Bank, 2014). Repeated service provision after contests, the situation studied in this paper, is commonly used in public procurement which represents around $20 \%$ of the GDP in OECD countries and around $14 \%$ in that of non-OECD countries (Audet, 2002). ${ }^{1}$ Public procurement is usually regulated with selection mechanisms that have a double role in the periodic provision of services. Firstly, they allow to increase competence (and reduce potential corruption) by challenging the incumbent's position in several degrees. For instance, the European Union's contracting rules establish three kinds of procedures (open, restricted and negotiated procedures) that guide the contracting authority in selecting an economic operator. Secondly, selection mechanisms can avoid shirking behaviours when the incumbent's past performance is taken into account in deciding future service providers. ${ }^{2}$ This last role is particularly important for contracting agencies that, given the intangible nature of services and the potential hindrances to the different contractual dimensions, find difficult to contract service effort and need to motivate the service provider not to shirk.

Past performance is one of the criteria that the contracting authority can take into account in addition to the cost bidder, the candidate's corporate social responsibility, etc. However, past performance usually has a low weighting in contests and, especially when Treasury is pressured, it is not taken into account and contracts are assigned to the lowest cost bidder. ${ }^{3}$ Omitting past performance in selecting a service provider can entail a moral hazard problem because service performance is intangible and difficult to demonstrate. As an example, consider a fireworks contest organized every July by the town council of Tarragona, Spain. The winner of this contest is hired to provide the fireworks in the town festival in September but is not allowed to participate in the next year's fireworks contest. As a consequence, it has been commonly recognized that contest winners perform higher quality fireworks during the contests than during the festival. Moreover, the contest can be designed according to the contracting authority's needs or ideology either to prevent candidates from exerting useless contest effort (to avoid, for example, lobbying) or, contrary, to demand a sunk contest effort such as an

\footnotetext{
${ }^{1}$ For example, in 2013 , the US government allocated 462.2 billion dollars to public procurement contracts (US Government Spending, 2014), and, in 2010, European countries allocated more than 420 billion euros to public procurement contracts (European Commission, 2011).

${ }^{2}$ Spagnolo (2012) analyses of the role and use of past performance in procurement, specially in US and Europe.

${ }^{3}$ Operators, however, can be excluded from future contests because they are bankrupt, have been found guilty of grave misconduct, etc.
} 
application fee or a service demonstration (prototypes, project drafts, etc.). The results from this paper show that introducing a biased contest that takes account of past performance could mitigate possible moral hazard problems at the service stages while respecting the principal's preferences over contest effort.

This paper focuses on a potentially repeated agency relationship between a designer and an incumbent to model a situation with repeated procurement of services. In period 1, there is an incumbent agent who provides a service (service 1). In period 2, there is a contest stage (contest 2) in which the designer chooses the provider of the second period service between two symmetric agents: the incumbent and his opponent. Effort at contest and service stages is observable by the three players (the designer, the incumbent and the opponent) but it is non-contractible. Thus, the incumbent has incentives to shirk in providing service 1. This paper analyses how contest 2 should be designed to mitigate moral hazard problems. Although service effort is non-contractible, the designer observes it and can induce the incumbent not to shirk by considering his service effort when deciding the next service provider. This is achieved by introducing a 'bias' that takes into account the incumbent's service 1 effort in the second period Contest Success Function (CSF). With such a biased contest, the designer can give an advantage (the bias) to the incumbent if he did not shirk at service $1 .^{4}$ The relationship between the bias (the service 1 effort) and the contest 2 effort is modelled by a Constant Elasticity of Substitution (CES) function. The CES function can describe linear and non-linear relationships between efforts and allows the designer to establish several types of bias, including additive and multiplicative biases which are the most used in the literature. Regarding the contest effort, the model distinguishes the two most common kinds of designer's preferences: either minimizing or maximizing contest effort. ${ }^{5}$ Both kinds of designer need contest 2 as an incentive mechanism to mitigate the moral hazard problem in the service stage. Notice that the designer can give priority to either optimizing contest effort or maximizing service effort depending on the designer's assessment in the procurement context. Since this study relies on a moral hazard problem in procurement of services, it is assumed that the designer's top priority is maximizing service effort. Then, the main objective of the analysis is to determine how the designer should choose the weight of service 1 effort (compared to contest 2 effort) and the degree of substitutability between efforts to maximize, firstly, the service effort and to optimize,

\footnotetext{
${ }^{4}$ Notice that this paper refers to any agent as he and to the designer as she.

${ }^{5}$ Usually, literature on contests assumes the designer wants to either minimize or maximize contest effort depending if such effort is either waste, as in a rent-seeking competition, or valuable, as in a promotion. See Epstein et al. (2011) for a general model in which the designer can have different preferences over contest effort.
} 
secondly, the total effort exerted by both agents in the contest stage according to the designer's preferences over contest effort.

On the one hand, when the designer considers contest effort wasteful, her optimal strategy is giving an infinite weight to service 1 effort in the CSF. Then, the incumbent can win contest 2 almost with certainty if he does not shirk in providing service 1 . This large advantage discourages both agents from competing while mitigates the moral hazard problem. Moreover, the designer should consider the incumbent's service and contest efforts as better substitutes because when efforts are perfect complements, not shirking in service 1 stops being an advantage and the moral hazard problem becomes more pronounced. On the other hand, when the designer considers contest effort valuable, it turns out that she should give the same weight to the service and contest efforts in the CSF. If service 1 effort is more (less) important than contest 2 effort, the incumbent has less incentives to exert high effort at contest 2 (service 1). Moreover, this kind of designer must choose the degree of substitutability between efforts according to their cost. When effort cost is low, the designer's optimal strategy is to consider both efforts as better substitutes. In this case, the incentive to shirk is weak because of the cheap effort and the incumbent's advantage from not shirking in service 1 is low enough to encourage both agents to compete at contest 2 . When effort cost increases, the degree of substitutability must decrease but not too much to give the service 1 provider an advantage neither too high (to discourage the opponent to compete at contest 2) nor too low (such that shirking in service 1 is advantageous for the incumbent).

Repeated moral hazard problems have been studied extensively in contract theory in order to mitigate this incentive problem between a principal and an agent (for reviews of the contract literature in repeated moral hazard problems see Bolton and Dewatripont, 2005; Chiapori et al, 1994; Laffont and Martimort, 2002; Laffont and Tirole, 1999). When effort is unobservable, the agent has private information about his own effort and he has incentives to shirk in providing a task for the principal. In this case, the principal can avoid moral hazard with a contract that links the agent's outcome with his pay-off. ${ }^{6}$ However, sometimes the agent's effort is observable but the principal cannot directly control such an effort because it is non-contractible. In this case, the agent also has incentives to shirk and the principal should introduce an incentive mechanism to avoid moral hazard problems. ${ }^{7}$ The most common incentives to mitigate repeated

\footnotetext{
${ }^{6}$ In contract renewal, there may be additional variables with an impact on this solution. For example, Iossa and Rey (2014) study the role of the duration of long-term contracts and Ohlendorf and Schmitz (2012) analyse the role of renegotiation of contract contingencies.

${ }^{7}$ When effort is observable but non-contractible, Gürtler and Kräkel (2010) shows that linking agent's effort with his pay-off might not be feasible. When the agent receives a bonus only if he does not shirk, there may be
} 
moral hazard problems consider, first, using agent's past effort to link this effort with his future pay-off and, second, introducing competition to enhance effort. ${ }^{8}$ This paper considers that agents' effort is observable but non-contractible and studies how the designer can avoid moral hazard problems in repeated procurement of services by introducing past effort as a bias in a contest to decide the next service provider.

The literature on contests analyses competitive situations in which agents exert sunk effort to maximize their probability of winning a prize. ${ }^{9}$ These models focus on agents' incentives to choose effort in the contest stage(s) but, although in many cases the contest winner and the contest designer enter into a principal-agent relationship after the contest, this conflict of interests in the service stage is not explicitly analysed. ${ }^{10}$ As an exception, Siegel (2010) considers that the winner of a contest must exert effort not only during the contest stage (unconditional effort) but also after the contest stage (conditional effort to winning). He labels this kind of contest simple contests. In his model, there is ex-ante commitment to exert a certain ex-post service effort. He finds that increasing the importance of the future service effort (relative to the current contest effort) in the contest increases agents' total equilibrium effort (contest and service). This paper extends such simple contests in two directions. Firstly, the ex ante commitment assumption is relaxed to allow an analysis with non-contractible effort. Secondly, repeated simple contests are considered to analyse how past service effort should be used in the contest design to solve moral hazard problems. Melkonyan (2013) considers a variation of Siegel's model in which contest and service efforts are related through a CES function. He also assumes that agents commit to future service effort (thus, there is no incentive problem in the service provision) and his results highlight the role of the degree of substitutability between service and contest effort in providing competition at the contest stage. This paper shows that the incentives from a biased contests are not trivial and depend on the expense of the effort, the degree of substitutability and the weight of past effort in the CSF. ${ }^{11}$

\footnotetext{
double-sided moral hazard. If the bonus is given before (after) the service performance, the agent (principal) has incentives to shirk (not to give the bonus).

${ }^{8}$ Hölmstrom, 1979 suggested firstly the use of reputation; Gibbons and Waldman, 1999 reviews literature on incentive provision by competition

${ }^{9}$ See Konrad (2009) for an overview of this literature.

${ }^{10}$ For example, Corchon and Dahm (2011) illustrate their model with the Olympic Games. Although the authors only consider the sunk efforts undertaken at the contest stage, they recognize that, once the Games are assigned, the quality of such Games is related to the effort that the host city exerts at the service stage. Then, there is a positive relationship between effort and service quality, and there may be a moral hazard problem when such effort is non-contractible. Other examples are Che and Gale (2003); Fullerton and McAfee (1999); Taylor (1995).

${ }^{11}$ Cesi and Albano (2008) also studies repeated service provision with moral hazard focussing on service effort and without considering repeated contests with sunk efforts.
} 
This paper is much related to literature on repeated biased contests. Meyer (1992) analyses promotions as incentive mechanisms through a model with two Lazear and Rosen (1981) contests and 'additive' biases. She finds that the principal's optimal choice to maximize total effort is to give an advantage to the previous winner in the second contest. This advantage implies a trade-off between effort competitions because there is a discouragement effect at the second contest. ${ }^{12}$ This trade-off is also found in repeated contests with 'multiplicative' bias. ${ }^{13}$ For example, Beviá and Corchón (2013) consider conflict situations with two contests where the probability of winning the first contest is introduced as a bias that multiplies agents' efforts in the second contest. These authors show that the discouragement effect in the second contest increases with the size of the bias. Therefore, to maximize total effort, the size of the bias is limited from below and above. ${ }^{14}$ In this paper, there is also a trade-off between service 1 and contest 2 efforts. However, the bias introduced in contest 2 is used to solve the moral hazard problem at the previous service stage rather than to increase total effort.

Regarding the different forms of introducing biases into a contest, Dahm and Porteiro (2008) analyzes a Tullock CSF with a general function that relates the bias with the contest effort. Special cases of this general function are the two most commonly used biases: the additive and multiplicative biases. These authors find that the additive bias decreases the stronger agent's incentives to exert high effort, while the multiplicative bias discourages the weaker agent. This paper considers a CES function in which a multiplicative bias implies that efforts are less substitutes than under an additive bias. Although this function is less general than the one used by Dahm and Porteiro (2008), it shows how agents' incentives change with the degree of substitutability and to what extent introducing a bias in the CSF under repeated procurement can mitigate the moral hazard problem at the service stage. ${ }^{15}$

The rest of this paper is organized as follows. The next section describes the model and the main results are provided in Section 3. Finally, concluding remarks are found in Section 4.

\footnotetext{
${ }^{12}$ Similarly, Kovenock and Roberson (2009) compares two electoral campaign strategies with a repeated biased contest in which the first winner has an additive advantage in the second contest. See Miller (2005) and Persson et al. (1997) as two examples of principal-agent models applied to Political Science.

${ }^{13}$ The multiplicative bias in the Tullock CSF was introduced by Clark and Riis (1998).

${ }^{14}$ Möller (2012) and Clark and Nilssen (2013) also find a similar trade-off considering learning effects that allow agents to increase their efficiency in future contests. Jofre-Bonet and Pesendorfer (2000) support empirically the existence of such learning effects for the case of highway paving contracts in California. Similar to learning effects, other authors consider pre-contest investment that allows agents to increase their efficiency in contests (see Fu and Lu, 2009; Münster, 2007). Finally, Konrad (2002) analyses the incentives of a biased all-pay auction in favour of an incumbent that, in addition, plays a role in determining the size of the prize.

${ }^{15}$ Ridlon and Shin (2013) also show that total contest effort is maximized with a multiplicative bias favouring (handicapping) the contest 1 winner when agents are homogeneous (heterogeneous). Alternatively, Moldovanu et al. (2012) introduce awards and punishments in the prize structure instead of biasing contests to maximize total contest effort.
} 


\section{The model}

Consider two periods, $t=1$ and $t=2$, and three players, a designer and two identical agents: the incumbent and his opponent. In period 1, the incumbent provides a service (service 1). In period 2, the designer selects either the incumbent or his opponent through a contest (contest 2) to provide the service in period 2. In each period, once the service is executed, all players observe the exerted effort in the service stage and the designer pays the service provider 1 monetary unit. Previously, in $t=0$, the designer decides the general setting of contest 2 to avoid moral hazard in service 1 . Notice that the service provider always shirks in period 2 because there is not future return of exerting high effort in service 2. Figure 1 summarizes the timing of the model.

The agents' strategies are their efforts, which are binary: high or low effort. ${ }^{16}$ At the $t$ period service stage (service $t$ ), the service incumbent (denoted by $I$ ) chooses his effort $s_{I, t} \in\{0,1\}$. At contest 2 , the service incumbent and his opponent (denoted by $O$ ) simultaneously choose their efforts; any agent $i$ 's effort is $e_{i, 2} \in\{0,1\} .{ }^{17}$ The same cost function is assumed for all stages and all periods with a positive constant $c$ multiplying effort, that is $c_{i, 2}\left(e_{i, 2}=1\right)=$ $c_{I, t}\left(s_{I, t}=1\right)=c>0$ and $c_{i, 2}\left(e_{i, 2}=0\right)=c_{I, t}\left(s_{I, t}=0\right)=0$. Given that effort is observable but non-contractible, the designer commits to pay the service provider even when he shirks at the service stage (chooses low effort).

Contestants are risk neutral and maximize their expected utility,

$$
\begin{gathered}
E U_{I, 1}=1-c_{I, 1}\left(s_{I, 1}\right)-c_{I, 2}\left(e_{I, 2}\right)+P_{I, 2} 1 \\
E U_{O, 2}=-c_{O, 2}\left(e_{O, 2}\right)+P_{O, 2} 1 .
\end{gathered}
$$

On the one hand, at period 1 , the incumbent agent $I$ exerts effort $s_{I, 1}$ and receives 1 monetary unit for providing service 1 . Given his effort, the incumbent wins contest 2 with probability $P_{I, 2}$ while the opponent agent $O$, who is not involved in period 1 , wins contest 2 with probability $P_{O, 2}$. The winner of contest 2 exerts low effort $\left(s_{w, 2}=0\right)$ in providing service 2 and receives 1 monetary unit.

The probability of winning contest 2 is the simple logistic CSF first introduced by Tullock

\footnotetext{
${ }^{16}$ Agents' effort can be interpreted as the quality of their activity. For example, Corchon and Dahm (2011) clarifies the positive relationship between quality and effort observing that the quality of Olympic Games increases with the investment of the hosting city.

${ }^{17}$ Assuming continuous efforts does not change the results substantially.
} 
$(1980),{ }^{18}$

$$
P_{i, 2}\left(\hat{e}_{I, 2}, \hat{e}_{O, 2}\right)=\left\{\begin{array}{ll}
\frac{\hat{e}_{i, 2}}{\hat{e}_{I, 2}+\hat{e}_{O, 2}} & \text { if } \hat{e}_{I, 2}+\hat{e}_{O, 2}>0 \\
\frac{1}{2} & \text { if } \hat{e}_{I, 2}+\hat{e}_{O, 2}=0
\end{array},\right.
$$

where $\hat{e}_{i, t}$ is the effective effort of agent $i$ at contest $2 .{ }^{19}$ The effective effort of the opponent is his current effort because he has no past. However, the designer can take into account the incumbents' service 1 effort in contest 2. Equation (4) defines the incumbent's effective effort which is a CES function,

$$
\hat{e}_{I, 2}=\left(\gamma s_{I, 1}^{\rho}+e_{I, 2}^{\rho}\right)^{1 / \rho} \quad \text { where } \gamma>0 \text { and } 0<\rho \leq 1
$$

On the one hand, $\gamma$ represents the weight that the designer gives to the past service effort $\left(s_{I, 1}\right)$. Past service effort can be more important $(\gamma \geq 1)$ or less important $(0<\gamma \leq 1)$ than current contest effort $\left(e_{I, 2}\right)$. On the other hand, $\rho$ determines the elasticity of substitution between efforts, which is equal to $1 /(1-\rho)$. This allows the designer to evaluate past and current effort not only as a linear combination, but also with more general relationships between efforts. When $\rho=1$, efforts $s_{I, 1}$ and $e_{I, 2}$ are perfect substitutes and the elasticity of substitution is infinite. At the other extreme, when $\rho \rightarrow-\infty$, efforts are perfect complements and the elasticity of substitution is zero. In general, the substitutability between efforts increases with $\rho$. Since equation (4) is not well defined when an effort is zero (low) while $\rho \leq 0$, we focus on $0<\rho \leq 1$. Notice also that efforts in equation (4) are additive when $\rho=1$ and multiplicative when $\rho \rightarrow 0 .^{20}$ When $0<\rho<1$, the relationship between past and current efforts is non-linear. As Figure 1 shows, in $t=0$ the designer makes public the contest 2 setting by choosing $\gamma$ and $\rho$.

The designer's objective is to choose the pair $(\rho, \gamma)$ that optimizes total effort in all periods. Firstly, the designer wants to maximize service effort. Secondly, she wants to maximize (minimize) contest effort because this effort is valuable (wasteful). Notice that these preferences are lexicographic: the designer prefers high effort in services (first priority) over optimizing effort in contests (secondary priority). The model is solved by backwards induction to find the Subgame

\footnotetext{
${ }^{18}$ The Tullock CSF is axiomatized by Skaperdas (1996), and Corchon and Dahm (2010) gives a microfoundation for this CSF. Contestants are uncertain about a characteristic of the decider (the designer) that is relevant for her decision in addition to effort. This fits our model because evaluating services of the same quality (effort) is rather subjective. Then, agents might win the contest probabilistically, and the Tullock CSF relates agents' efforts with their win probabilities.

${ }^{19}$ Under the alternative assumption that the win probability is zero when no agent exerts effort, analogous results to Lemma 1 (below) hold.

${ }^{20}$ Notice that the marginal ratio of technical substitution of $s_{I, 1}^{\gamma} e_{I, 2}$ and equation (4) converge when $\rho \rightarrow 0$ and, therefore, $\hat{e}_{I, 2} \rightarrow s_{I, 1}^{\gamma} e_{I, 2}$ when $\rho \rightarrow 0$ (see page 20 in Varian, 1992). See Clark and Riis (1998) for an axiomatic foundation of the CSF in (4) for the case $\rho \rightarrow 0$.
} 
Perfect Equilibria (SPE) in behaviour strategies.

The case where $\gamma=0$ is equivalent to not considering past service effort in contest 2 . In this case, the incumbent's effective effort from equation (4) becomes his current effort at contest 2 , $\hat{e}_{I, 2}=e_{I, 2}$. Then, the incumbent always shirks at service 1 because his expected future pay-off does not depend on his past effort. However, at contest 2 both agents would like to compete as long as effort is cheap enough. This result is formalized in Lemma 1 (a proof can be found in Appendix 5.1). ${ }^{21}$

Lemma 1 Consider $\gamma=0$. There is always moral hazard because the incumbent agent always shirk at the service stage. Behaviours at contest 2 depend on the effort cost, more precisely:

- When effort cost is low, $c<1 / 2$, the unique SPE has both agents exerting high effort at contest 2 (maximum contest effort).

- When effort cost is high, $c>1 / 2$, the unique SPE has both agents exerting low effort at contest 2 (minimum contest effort).

It should be noted that, apart from the functional form specified in equation (3), the studied situation is a special case of a Siegel (2010) simple contest in which commitment is not assumed. First, agents exert effort at contest 2 (the unconditional or sunk cost) and, then, the winner has to exert effort at service 2 (the conditional cost to winning). ${ }^{22}$

The next section focuses on the potential repeated relationship between the designer and the incumbent in period 2. In such a context, the designer can avoid the moral hazard problem at service 1 by considering the incumbent's past effort when resolving contest 2 . The conditions under which this potentially repeated relationship is most effective are analysed. From Lemma 1 we know that when the effort cost is high $(c>1 / 2)$, there is no incentive to compete at the contest stage and moral hazard at service 1 cannot be avoided. Therefore, in what follows, we focus on the case $c<1 / 2$ to analyse optimal procurement design under repeated contracting.

\footnotetext{
${ }^{21}$ When $c=1 / 2$, agents are completely indifferent about their effort choice at contest 2 . There is, hence, a multiplicity of equilibria in behaviour strategies. Since the situation is symmetric, focusing on symmetric behaviour strategies opens the door for agents choosing any probability of entering the contest 'in between' the two pure strategies described in Lemma 1.

${ }^{22}$ In Siegel (2010), the parameter $0 \leq \alpha \leq 1$ represents the part of the cost which is sunk and $C$ is the total cost of the game for the winner. Then, $\alpha C=c_{i}\left(e_{i}\right)$ is the sunk cost at the contest stage and $(1-\alpha) C=c_{I}\left(s_{I}\right)$ is the conditional cost exerted by the winner (the service provider) at the next service stage. Given that Siegel does not allow for shirking at the next service stage, our setting reduces to $c_{I}\left(s_{I}=1\right)=c_{i}\left(e_{i}=1\right)=c$. Equation (1), thus, is a special case of Siegel's setting in which $C=2 c$ and $\alpha=1 / 2$.
} 


\section{Results}

Consider the designer's problem of the optimal choice of $\gamma$ and $\rho$ that determine the bias of contest 2 through the incumbent's effective effort from equation (4). The designer can weight the incumbent's past (service) effort differently from current (contest) effort in the CSF with $\gamma$. Moreover, the designer can determine the elasticity of substitution between efforts with $\rho$.

At contest 2, the agents' probabilities of winning depend on the effective effort in equation (4). If the incumbent shirked in providing service 1 , his effective effort at contest 2 is his current effort for any pair $(\gamma, \rho)$. Then, both agents are in equal conditions and their behaviour strategies are exerting high contest effort (see Lemma 1). If the incumbent did not shirk in providing service 1, the agents' behaviour strategies depend on the incumbent's advantage of exerting high effort twice: at service $1\left(s_{I, 1}=1\right)$ and at contest $2\left(e_{I, 2}=1\right)$. In this case, the incumbent's effective effort from equation (4) becomes $\hat{e}_{I, 2}=(\gamma+1)^{1 / \rho}$. Efforts $s_{I, 1}$ and $e_{I, 2}$ are perfect substitutes when $\rho=1$ and the incumbent's effective effort can be, as maximum, equal to $\gamma+1$. When $\rho<1$, some complementarity between efforts is introduced and the incumbent's effective effort is larger than $\gamma+1 .^{23}$ Notice that if the incumbent exerts high effort twice and his opponent exerts high effort at contest 2 , the incumbent's win probability is $(\gamma+1)^{1 / \rho}$ times his opponent's one and this advantage increases exponentially when $\rho$ decreases. Thus, when the substitutability degree decreases ( $\rho$ decreases), the incumbent's incentive to exert high effort at both stages becomes stronger because the return is larger. At service 1, whether the moral hazard problem can be avoided depends on the effort cost $(c)$, the weight of past effort $(\gamma)$ and the level of substitutability between efforts $(\rho)$. For a better explanation of the interaction of these three elements, the resulting SPE are described for $\gamma \leq 1$ and $\gamma \geq 1$.

Consider first the case in which service 1 effort has a lower weight than contest 2 effort $(\gamma \leq 1)$ in equation $(4)$. It turns out that the moral hazard problem is mitigated for any level of substitution between past and current efforts with certainty only if effort is cheap enough. When effort is more expensive, the designer can avoid the moral hazard problem in service 1 by decreasing the level of substitutability between efforts to the detriment of competition in contest 2. The lower the parameter $\gamma$, the more severe the moral hazard problem. Proposition 1 states the results formally (all calculations are in Appendix 5.2).

Proposition 1 For $c<1 / 2, \gamma \leq 1$ and any $0<\rho \leq 1$, introducing a biased contest can avoid moral hazard at service 1. Three different types of SPE exist:

\footnotetext{
${ }^{23}$ The cause of this implication is that $\gamma+1$ is larger than one. Given that the effective effort $(\gamma+1)^{1 / \rho}$ is convex for $\rho \in(0,1]$, it increases when $\rho$ decreases.
} 
SPE I When $c<\min \left\{1 /\left[(\gamma+1)^{1 / \rho}+1\right],(\gamma+1)^{1 / \rho} /\left[(\gamma+1)^{1 / \rho}+1\right]-1 / 2\right\}$, moral hazard is mitigated and contest effort is maximum. The unique SPE has the incumbent not shirking at service 1 and both agents exerting high effort at contest 2.

SPE II When $\max \left\{\left[(\gamma+1)^{1 / \rho}-\gamma^{1 / \rho}\right] /\left[2(\gamma+1)^{1 / \rho}+2\right], 1 /\left[(\gamma+1)^{1 / \rho}+1\right]\right\}<c<1 / 2$ and/or $(\gamma+1)^{1 / \rho} /\left[(\gamma+1)^{1 / \rho}+1\right]-1 / 2<c<1 /\left[(\gamma+1)^{1 / \rho}+1\right]$, moral hazard cannot be avoided and contest effort is maximum. The unique SPE has the incumbent shirking at service 1 and both agents exerting high effort at contest 2.

SPE III When $1 /\left[(\gamma+1)^{1 / \rho}+1\right]<c<\left[(\gamma+1)^{1 / \rho}-\gamma^{1 / \rho}\right] /\left[2(\gamma+1)^{1 / \rho}+2\right]$, moral hazard is mitigated and contests effort is not maximum. The unique SPE has the incumbent not shirking at service 1 and exerting high effort at contest 2 with probability $r_{I, 2}=$ $\left(2^{1 / \rho}+1\right) /\left(2^{1 / \rho}-1\right)-2 c\left(2^{1 / \rho}+1\right) /\left(2^{1 / \rho}-1\right)$. At contest 2, his opponent exerts high effort with probability $q_{O, 2}=2 c\left(2^{1 / \rho}+1\right) /\left(2^{1 / \rho}-1\right)$.

Figure 2 illustrates the regions for each SPE in Proposition 1 when $\gamma=0.8$. In order to develop an intuition for the results, consider first the right area of Figure 2 in which $\rho$ is high and efforts $s_{I, 1}$ and $e_{I, 2}$ are better substitutes. Since the incumbent's advantage of exerting high effort twice increases when $\rho$ decreases, this advantage is relatively small in this area, $(\gamma+1)^{1 / \rho} \leq 2 \gamma^{1 / \rho}+1$. This small advantage does not discourage the opponent from exerting high effort at contest 2. Meanwhile, the incumbent is more willing to exert high effort twice for higher effort costs when $\rho$ decreases as long as effort cost is relatively cheap. When effort is expensive enough, the incumbent chooses to exert high effort only once. In such a case, his optimal strategy is to shirk at service 1 and to exert high effort at contest 2 because, when $\gamma \leq 1$, current effort is more important than past effort in equation (4). ${ }^{24}$ The thin solid line in Figure 2 separates the area in which the service 1 incumbent is willing to exert high effort twice (SPE I) from the area in which he exerts high effort only once (SPE II). Now consider the left of Figure 2 in which $\rho$ is low and efforts are less substitutes. Here, the incumbent's advantage of exerting high effort twice is relatively large, $(\gamma+1)^{1 / \rho}>2 \gamma^{1 / \rho}+1$. When the designer decreases $\rho$, the service 1 incumbent's probability of winning contest 2 increases exponentially if he exerts high effort twice while the opposite effect is found for his opponent. The thick solid line represents the first effect while the dashed thin line represents the latter one. Between these two lines there is SPE III in which the incumbent never shirks in providing service 1 and

\footnotetext{
${ }^{24}$ When $\gamma \leq 1$, exerting high effort only at contest 2 is not optimal for the incumbent. If he does so, his effective effort from equation (4) becomes $(\gamma)^{1 / \rho}$ which decreases when $\rho$ also decreases.
} 
both agents play mixed strategies at contest 2 . When $c=1 /\left(2 \gamma^{1 / \rho}+2\right)$, both agents have the same probability of exerting high effort at contest 2 . If effort cost increases, the incumbent has fewer incentives to compete and, consequently, his opponent has more incentives to exert high effort. If, however, effort cost is lower than $1 /\left(2 \gamma^{1 / \rho}+2\right)$, the incumbent has more incentives to compete and the incumbent's large advantage discourages his opponent from competing.

Notice from Proposition 1 that SPE I can be achievable for the maximum effort cost $c<1 / 4$ when $(\gamma, \rho)=(\gamma, \ln (\gamma+1) / \ln 3) .{ }^{25}$ For example, when $\gamma=0.8(\gamma=1)$, SPE I is achievable for any cost $c<1 / 4$ if $\rho=\ln 1.8 / \ln 3 \approx 0.53(\rho=\ln 2 / \ln 3 \approx 0.63)$. Observe that, in order to achieve SPE I for $c<1 / 4$, the level of substitutability between efforts must decrease to compensate a lower weight of past effort in equation (4).

Consider now the case in which service 1 effort has a higher weight than contest 2 effort $(\gamma \geq 1)$ in equation $(4)$. In this case, for any $c<1 / 2$ the moral hazard problem is mitigated to the detriment of competition in contest 2 . The incumbent's advantage of not shirking at service 1 can be so large that reduces his incentives to compete at contest 2 for higher effort cost and can even preempt his opponent in competing at contest 2. Proposition 2 states these results formally (all calculations are in Appendix 5.2).

Proposition 2 For $c<1 / 2, \gamma \geq 1$ and any $0<\rho \leq 1$, introducing a biased contest always avoids moral hazard at service 1. Four different types of SPE exist:

SPE I When $c<\min \left\{\left[(\gamma+1)^{1 / \rho}-\gamma^{1 / \rho}\right] /\left[\left(\gamma^{1 / \rho}+1\right)\left((\gamma+1)^{1 / \rho}+1\right)\right], 1 /\left[(\gamma+1)^{1 / \rho}+1\right]\right\}$, moral hazard is mitigated and contest effort is maximum. The unique SPE has the incumbent not shirking at service 1 and both agents exerting high effort at contest 2.

SPE III When $1 /\left[(\gamma+1)^{1 / \rho}+1\right]<c<\left[(\gamma+1)^{1 / \rho}-\gamma^{1 / \rho}\right] /\left[\left(\gamma^{1 / \rho}+1\right)\left((\gamma+1)^{1 / \rho}+1\right)\right]$, moral hazard is mitigated and contest effort is not maximum. The unique SPE has the incumbent not shirking at service 1 and exerting high effort at contest 2 with probability $r_{I, 2}=\left(2^{1 / \rho}+1\right) /\left(2^{1 / \rho}-1\right)-2 c\left(2^{1 / \rho}+1\right) /\left(2^{1 / \rho}-1\right)$. At contest 2 , his opponent exerts high effort with probability $q_{O, 2}=2 c\left(2^{1 / \rho}+1\right) /\left(2^{1 / \rho}-1\right)$.

SPE IV When $\left[(\gamma+1)^{1 / \rho}-\gamma^{1 / \rho}\right] /\left[\left(\gamma^{1 / \rho}+1\right)\left((\gamma+1)^{1 / \rho}+1\right)\right]<c<1 /\left(\gamma^{1 / \rho}+1\right)$, moral hazard is mitigated and contest effort is not maximum. The unique SPE has the incumbent

\footnotetext{
${ }^{25}$ Regarding the effort cost that describe the region of SPE I in Proposition 1, it turns out that SPE I is achievable for $c<1 /\left[(\gamma+1)^{1 / \rho}+1\right]$ when $(\gamma+1)^{1 / \rho} \geq 3$. Rearranging this last condition, we can find that $1 /\left[(\gamma+1)^{1 / \rho}+1\right] \leq 1 / 4$. Similarly, SPE I is achievable for $c<(\gamma+1)^{1 / \rho} /\left[(\gamma+1)^{1 / \rho}+1\right]-1 / 2$ when $(\gamma+$ $1)^{1 / \rho} \leq 3$. Rearranging this last condition, we can find that $(\gamma+1)^{1 / \rho} /\left[(\gamma+1)^{1 / \rho}+1\right]-1 / 2 \leq 1 / 4$. Therefore, when $(\gamma+1)^{1 / \rho}=3$ or $\rho=\ln (\gamma+1) / \ln 3$, SPE I is achievable for any $c<1 / 4$.
} 
not shirking at service 1 and exerting low effort at contest 2. At contest 2, his opponent exerts high effort.

SPE V When $1 /\left(\gamma^{1 / \rho}+1\right)<c<1 / 2$, moral hazard is mitigated and contests effort is minimum. The unique SPE has the incumbent not shirking at service 1 and no agent exerting high effort at contest 2.

Figure 3 illustrates the regions for each SPE in Proposition 2 when $\gamma=1.2$. When $\rho$ is high and efforts are better substitutes (right area), the incumbent's advantage of exerting high effort twice is relatively small, $(\gamma+1)^{1 / \rho} \leq 2 \gamma^{1 / \rho}+1$. As in the previous case, the opponent is willing to exert high effort at contest 2 as long as the incumbent's advantage is relatively small. When $\rho$ decreases, the incumbent is more willing to exert high effort twice for higher effort costs as long as effort cost is relatively cheap. There is SPE I for lower effort costs but this SPE is achievable for a maximum cost lower than $1 / 4 .{ }^{26}$ When effort is expensive enough, exerting high effort twice is too expensive and the incumbent chooses exerting high effort only at service 1 because when $\gamma \geq 1$, past effort is more important than current effort in equation (4). The solid line in Figure 3 separates the area in which the incumbent is willing to exert high effort twice (SPE I) from the area in which he exerts high effort only once (SPE IV). ${ }^{27}$ In SPE IV, the incumbent's effective effort from equation (4) becomes $\gamma^{1 / \rho}$ which increases exponentially when $\rho$ decreases. Therefore, his opponent has less incentives to compete at contest 2 when efforts are less substitutes. ${ }^{28}$ The dotted line in Figure 3 separates the regions in which the opponent competes at contest 2 (SPE IV) from the region in which he does not (SPE V). ${ }^{29}$ When $\rho$ is low and efforts are more complementary (left area), the incumbent's advantage of exerting high effort twice is relatively high, $(\gamma+1)^{1 / \rho}>2 \gamma^{1 / \rho}+1$, and increases more when $\rho$ decreases. The dashed (thick solid) line in Figure 3 represents the exponential decrease (increment) of

\footnotetext{
${ }^{26}$ Regarding the effort cost that describe the SPE regions in Proposition 2, it turns out that when the incumbent's return of exerting high effort twice is low, $(\gamma+1)^{1 / \rho} \leq 2 \gamma^{1 / \rho}+1$, SPE I is achievable when $c<\left[(\gamma+1)^{1 / \rho}-\gamma^{1 / \rho}\right] /\left[\left(\gamma^{1 / \rho}+1\right)\left((\gamma+1)^{1 / \rho}+1\right)\right]<1 / 4$. Similarly, when the incumbent's return of exerting high effort twice is high, $(\gamma+1)^{1 / \rho}>2 \gamma^{1 / \rho}+1$, SPE I is achievable when $c<1 /\left[(\gamma+1)^{1 / \rho}+1\right]<1 / 4$. In both cases SPE I is achievable for a higher cost boundary lower than $1 / 4$.

${ }^{27}$ Figure 4 represents the case in which service 1 and contest 2 efforts have the same weight $(\gamma=1)$ in equation (4). When efforts are better substitutes (right area) and effort cost increases, the incumbent has less incentives to exert high effort twice. When effort is expensive enough, he decides to exert high effort only once but is indifferent between $s_{I, 1}$ and $e_{I, 2}$ because both efforts have the same weight. Then, there is multiplicity of equilibria and SPE II coexists with SPE IV when $\left[(\gamma+1)^{1 / \rho}-\gamma^{1 / \rho}\right] /\left[\left(\gamma^{1 / \rho}+1\right)\left((\gamma+1)^{1 / \rho}+1\right)\right]<c<1 /\left(\gamma^{1 / \rho}+1\right)$.

${ }^{28}$ When the incumbent exerts high effort only at service 1 , his effective effort $\gamma^{1 / \rho}$ is convex for $\rho \in(0,1]$ only if $\gamma \geq 1$. This advantage increases when $\rho$ decreases.

${ }^{29}$ Notice that there is not SPE V when $\gamma=1$ because the condition $1 /\left(\gamma^{1 / \rho}+1\right)<c<1 / 2$ from Proposition 2 does not hold.
} 
the opponent's (incumbent's) win probability when $\rho$ decreases. Between the solid thick line and the dashed line there is SPE III where moral hazard is mitigated and agents play mixed strategies at contest 2 .

Notice from Proposition 2 that the region of SPE V increases with the size of $\gamma$. When $\gamma \rightarrow \infty$ in equation (4), the size of the incumbent's advantage is so large that it discourages both agents from competing at contest 2 for any effort cost. Proposition 3 states this result formally (all calculations are in Appendix 5.3).

Proposition 3 When $\gamma \rightarrow \infty, 0<\rho \leq 1$ and $c<1 / 2$, potential repetition avoids moral hazard at service 1. At contest 2 there is no agent exerting high effort. This unique SPE has been named SPE V in Proposition 2.

Table 1 compares the obtained SPE in Propositions 1, 2 and 3. SPE I, III, IV and V avoid moral hazard at service 1 while SPE II does not. Regarding total contest effort, SPE I and II have the maximum total contest effort while SPE V has the minimum. In between, SPE III has a higher contest effort than SPE IV. The obtained results allow the designer to choose the optimal pair $(\gamma, \rho)$ according to her preferences over the SPE. On the one hand, a designer who wants to minimize contest effort in addition to maximize service effort has the following preference relationship over the SPE: SPEV $\succ S P E I V \succ S P E I I I \succ S P E I \succ S P E I V \succ S P E I I$. The optimal strategy of this designer is considering high service 1 effort as the only relevant effort in deciding the service 2 provider, that is $\gamma \rightarrow \infty$. Then, her most preferred outcome, SPE V, is obtained for any $c<1 / 2$ as Proposition 3 shows. On the other hand, a designer who wants to maximize contest effort in addition to service effort has the following preference relationship over all the SPE: $S P E I \succ S P E I I I \succ S P E I V \succ S P E V \succ S P E I I$. When effort cost is relatively low, the designer can obtain her most preferred outcome, SPE I, for the maximum effort cost $c<1 / 4$ by considering the incumbent's past and current efforts equally important but reducing the level of substitution between them, concretely she must state $(\gamma, \rho)=(1, \ln 2 / \ln 3) .{ }^{30}$ For larger values of effort cost, the designer can then obtain her second most preferred outcome, SPE III, by reducing the level of substitutability. Concretely, for $\gamma=1$ and $1 / 4<c<1 / 2$, the designer must choose as much the level of substitutability $\rho<\ln (2) / \ln ((2 c-1) /(1-2 c))$ to guarantee SPE III. ${ }^{31}$ In this situation, it seems that the designer should reduce the degree

\footnotetext{
${ }^{30}$ The same result can be obtained with $\gamma<1$ but compensating this lower weight of past effort with a higher level of complementarity that increases the incumbent's advantage, $(\gamma, \rho)=(\gamma, \ln (\gamma+1) / \ln 3)$.

${ }^{31}$ Consider the upper effort cost that defines SPE III when $\gamma=1$ from Proposition 1 or 2 , that is $c<$ $\left(2^{1 / \rho}-1\right) /\left[2\left(2^{1 / \rho}+1\right)\right]$. Isolating $\rho$ from this upper effort cost, we find the maximum level of substitution
} 
of substitutability to the minimum for obtaining SPE III. However, as it is explained below, considering past and current efforts as perfect complements is never an optimal choice for any of both kinds of designer.

Consider the limit case $\rho \rightarrow 0$ in which the incumbent's effective effort becomes

$$
\hat{e}_{I, 2}=s_{I, 1}^{\gamma} e_{I, 2}
$$

Note that, as when efforts are perfect complements, equation (5) gives the minimum effort between $s_{w, 1}$ and $e_{w, 2}$ because of the assumed values for the binary effort. If either effort is equal to zero, the incumbent's effective effort is equal to zero. If both efforts are high, the incumbent's effective effort is never higher than 1 . Therefore, this effective effort does not give any advantage to the incumbent at contest 2 . In addition, this effective effort excludes the incumbent from contest 2 if he exerts low effort in either service 1 or contest 2 . Therefore, this effective effort with $\rho \rightarrow 0$ gives the same outcome than considering past and current efforts as perfect complements with $\rho \rightarrow-\infty$. The results show that SPE I is achievable for cheaper effort but moral hazard cannot be avoided for higher values of effort cost. Proposition 4 states these results formally (all calculations are in Appendix 5.4).

Proposition 4 For $c<1 / 2, \gamma>0$ and $\rho \rightarrow 0$, introducing a biased contest can avoid moral hazard at service 1. Two different types of SPE exist:

SPE I When $c<1 / 4$, moral hazard is mitigated and contest effort is maximum. The unique SPE has the incumbent not shirking at service 1 and both agents exerting high effort at contest 2 .

SPE VI When $1 / 4<c<1 / 2$, moral hazard cannot be avoided and contest effort is not maximum. The unique SPE has the incumbent shirking at service 1 and only his opponent exerting high effort at contest 2.

In equilibrium, the service 1 incumbent always chooses $s_{w, 1}=e_{w, 2}$ when the incumbent's effective effort in contest 2 is equation (5). Since the incumbent has no advantage at contest 2 , his opponent always exerts high effort for any $c<1 / 2$. When effort is cheap enough, the incumbent still has incentives to exert high effort twice and SPE I is achievable for $c<1 / 4$. When effort cost increases and it is too expensive to exert high effort twice, the incumbent's

required to obtain SPE III at its maximum effort cost, $\rho<\ln 2 / \ln ((2 c-1) /(1-2 c))$. For example, if $c=1 / 3$ $(c=49 / 100)$, the designer should consider $\rho<\ln 2 / \ln 5 \approx 0.43(\rho<\ln 2 / \ln 99 \approx 0.15)$ in order to obtain SPE III instead of SPE II or IV. 
optimal strategy is to exert low effort at service 1 and contest 2 stages. Then, there is SPE VI which has the incumbent shirking at service 1 and only his opponent exerting high effort at contest 2 .

The discontinuity between the results of Proposition 4 and Propositions 1 and 2 is due to the assumption of binary effort. This model cannot analyze the negative interval $\rho \in(-\infty, 0]$. However, the effective effort from equation (5) gives the same outcome that perfect complement efforts and, thus, the limit case $\rho \rightarrow 0$ is explaining the same results than the limit case $\rho \rightarrow-\infty$. The results of Proposition 4 are explanatory enough to conclude that increasing complementarities between efforts avoids moral hazard as long as such level of complementarity is not too high and effort is cheap enough. The two kinds of designer considered in this paper should avoid perfect complement efforts because, then, not shirking in providing service 1 stops being an advantage for the incumbent and becomes a condition to participate in contest $2 .^{32}$ Therefore, the moral hazard problem is less (more) severe when the degree of substitutability in equation (4) is high (low) enough.

Regarding only the two most common biases used by the literature (the multiplicative and additive biases), in this model the designer's optimal strategy is stating an additive bias instead of a multiplicative bias to mitigate moral hazard problems. The multiplicative bias corresponds to considering efforts as perfect complements and does not provide the correct incentives to avoid moral hazard when effort cost increases. However, the additive bias provides an advantage to the incumbent that increases the probability of avoiding moral hazard, although it may dampen the competition at contest 2. Overall, for the analysed model, a designer who wants to minimize contest effort in addition to maximize service effort should consider the incumbent's past and current efforts as perfect substitutes in the second period CSF. Moreover, she must give a high weight to past effort specially when effort is expensive. A designer who wants to maximize contest effort in addition to service effort should consider the incumbent's past and current efforts as equally important and, moreover, she must reduce the level of substitutability when effort cost increases. ${ }^{33}$ Corollary 1 summarizes the designer's optimal strategy according to her preferences over contest effort.

\footnotetext{
${ }^{32}$ Table 1 shows the outcome of Propositions 1, 2, 3 and 4. A designer who minimizes (maximizes) contest effort has the following preference relationship over SPE: SPEV $\succ S P E I V \succ S P E I I I \succ S P E I \succ S P E V I \succ S P E I I$ $(S P E I \succ S P E I I I \succ S P E I V \succ S P E V \succ S P E I I \succ S P E V I)$.

${ }^{33}$ Suppose a designer who wants to maximize the sum of efforts in all stages having no priorities over contest and service efforts. Then, her preferences over all SPE are: SPEI $\succ S P E I I I \succ S P E I I \sim S P E I V \succ S P E V \sim$ $S P E V I$. Notice that this designer should follow the same strategy than a designer with lexicographic preferences who wants to maximize, firstly, service effort and, secondly, contest effort.
} 
Corollary 1 For $c<1 / 2, \gamma>0$ and $0<\rho \leq 1$, taking into account service 1 effort in the CSF of contest 2 mitigates the moral hazard problem. Consider the designer's optimal strategy when she wants to maximize, firstly, service effort and optimize, secondly, contest effort.

- A designer who minimizes contest effort chooses $\gamma \rightarrow \infty$ and $\rho=1$ to achieve her most preferred outcome, SPE $V$, for any effort cost.

- A designer who maximizes contest effort chooses $(\gamma, \rho)=(1, \ln 2 / \ln 3)$ to achieve her most preferred outcome, SPE I, for any $c<1 / 4$. For higher effort cost, choosing $(\gamma, \rho)=$ $(1, \ln ((2 c-1) /(1-2 c))-\epsilon)$ is optimal to achieve her second preferred outcome, SPE III.

\section{Conclusions}

This paper studies a moral hazard problem in repeated procurement of services by a model with two periods and two homogeneous and risk-neutral agents. In the first period, there is an incumbent that provides a service. In the second period, the incumbent is challenged by an opponent for providing a future service. The designer wants to maximize service effort and chooses how to bias the contest to mitigate the moral hazard problem. In the contest, past service effort is considered as a bias and a CES function relates the incumbent's past service effort with his current contest effort. On the one hand, when contest effort is wasteful, it is shown that the designer's optimal choice is to consider service 2 effort as the only relevant effort in the contest stage when the provider of service 1 did not shirk. On the other hand, when contest effort is valuable for the designer, the designer's optimal choice is to consider service and contest efforts equally important and more (less) substitutes when effort cost is low (high).

The results of this paper provide some valuable insights into how to improve procedures commonly applied in repeated provision of services. Past performance should be taken into account in the design of future contests to mitigate moral hazard problems although it can disincentive competition in future contests. Therefore, it becomes particularly important to determine the optimal degree to which contests should be biased towards past performance when the designer values contest effort. It turns out that when effort cost increases for the agents, the designer should increase the incumbent's advantage for former high performance (i.e., allow for a lower degree of substitutability in the CSF) to mitigate the moral hazard problem at the expense of reducing future competition.

Some interesting extensions of the model are left for future research, such as the role of risk aversion, heterogeneous agents and different CSF in the determination of the optimal bias. 


\section{Appendix}

\subsection{Proof of Lemma 1: $\gamma=0$ and $0<\rho \leq 1$}

At contest 2, the service 1 incumbent and his opponent compete for providing low effort at service 2 and obtaining 1 monetary unit. Since $\gamma=0$, both agents have the same effective effort in contest 2 , see equation (4). The following table shows the expected utility of both agents at contest 2, $E U_{I, 2}\left(e_{I, 2}, e_{O, 2}\right)$ on the left side and $E U_{O, 2}\left(e_{I, 2}, e_{O, 2}\right)$ on the right side, for each possible combination of agents' binary effort.

\begin{tabular}{|c|c|c|}
\cline { 2 - 3 } \multicolumn{1}{c|}{} & $e_{O, 2}=0$ & $e_{O, 2}=1$ \\
\hline$e_{I, 2}=0$ & $\frac{1}{2}, \frac{1}{2}$ & $0,1-c$ \\
\hline$e_{I, 2}=1$ & $1-c, 0$ & $\frac{1}{2}-c, \frac{1}{2}-c$ \\
\hline
\end{tabular}

Table A.1. Agents' expected utilities at contest 2 when $\gamma=0\left(E U_{I, 2}\right.$ on the left and $E U_{O, 2}$ on the right).

The agents' behaviour strategies at the contest stage depend on how expensive effort is. When effort cost is lower (higher) than $1 / 2$, exerting high (low) effort is optimal for both agents. When effort cost is equal to $1 / 2$, both agents are indifferent between exerting high or low effort.

At service 1, the incumbent's service effort does not have an impact on his future payoff, that is, on $E U_{I, 2}$. Therefore, he prefers shirking to not shirking in providing service 1 $\left(1+E U_{I, 2}\left(e_{I, 2}, e_{O, 2}\right)>1-c+E U_{I, 2}\left(e_{I, 2}, e_{O, 2}\right)\right.$. The obtained SPE can be described by the sequence of efforts on the path $\left\{\left(s_{I, 1}\right),\left(e_{I, 2}, e_{O, 2}\right)\right\}$,

$$
\begin{cases}\{(0),(1,1)\} & \text { if } 0<c<\frac{1}{2} \\ \left\{(0),\left(r_{I, 2}, q_{O, 2}\right)\right\} & \text { if } c=\frac{1}{2}, \text { where } r_{I, 1} \in[0,1] \text { and } q_{O, 2} \in[0,1] \\ \{(0),(0,0),(0)\} & \text { if } c>\frac{1}{2}\end{cases}
$$

where $r_{I, 2}\left(q_{O, 2}\right)$ is the probability that agent $I(O)$ exerts high effort in contest 2.

\subsection{Proof of Propositions 1 and 2: $\gamma>0$ and $0<\rho \leq 1$}

At contest 2, the incumbent's effective effort from equation (4) depends on his effort in providing service 1 . On the one hand, if the incumbent shirked at service $1\left(s_{I, 1}=0\right)$, his effective effort is his current effort $e_{I, 2}$. Then, from Lemma 1, it is known that both agents exert high effort at contest 2 when $c<1 / 2$ and that the incumbent's expected utility is $E U_{I, 2}\left(\left(e_{I, 2}, e_{O, 2}\right) \mid s_{I, 1}=\right.$ 
$0)=1 / 2-c$ (see Table A.1). On the other hand, if the incumbent did not shirk in providing service $1\left(s_{I, 1}=1\right)$, his effective effort from equation (4) is equal to $\left(\gamma+e_{I, 2}^{\rho}\right)^{1 / \rho}$. Table A.2 summarizes the expected utility of both agents, $E U_{I, 2}\left(\left(e_{I, 2}, e_{O, 1}\right) \mid s_{I, 1}=1\right)$ on the left and $E U_{O, 2}\left(\left(e_{I, 2}, e_{O, 1}\right) \mid s_{I, 1}=1\right)$ on the right, for any combination of agents' binary effort at contest 2 .

\begin{tabular}{|c|c|c|}
\cline { 2 - 3 } \multicolumn{1}{c|}{} & $e_{O, 2}=0$ & $e_{O, 2}=1$ \\
\hline$e_{I, 2}=0$ & 1,0 & $\frac{\gamma^{1 / \rho}}{\gamma^{1 / \rho}+1}, \frac{1}{\gamma^{1 / \rho}+1}-c$ \\
\hline$e_{I, 2}=1$ & $1-c, 0$ & $\frac{(\gamma+1)^{1 / \rho}}{(\gamma+1)^{1 / \rho}+1}-c, \frac{1}{(\gamma+1)^{1 / \rho}+1}-c$ \\
\hline
\end{tabular}

Table A.2. Agents' expected utilities at contest 2 when $s_{I, 2}=1$ for any $\gamma>0,0<\rho \leq 1$ ( $E U_{I, 2}$ on the left and $E U_{O, 2}$ on the right).

Notice that the incumbent's dominant strategy is $e_{I, 2}=0$ when effort cost is high enough,

$$
c>\frac{(\gamma+1)^{1 / \rho}-\gamma^{1 / \rho}}{\left[(\gamma+1)^{1 / \rho}+1\right]\left(\gamma^{1 / \rho}+1\right)} .
$$

Otherwise, his behaviour strategy depends on the opponent's strategy. Meanwhile, the opponent's dominant strategy is $e_{O, 2}=1$ when effort cost is low enough,

$$
c<\frac{1}{(\gamma+1)^{1 / \rho}+1}
$$

and his dominant strategy is $e_{O, 2}=0$ when effort cost is too high,

$$
c>\frac{1}{\gamma^{1 / \rho}+1}
$$

For intermediate effort costs between the thresholds of equations (8) and $(9), 1 /\left[(\gamma+1)^{1 / \rho}+1\right]<$ $c<1 /\left(\gamma^{1 / \rho}+1\right)$, the opponent's behaviour strategy depends on the incumbent's strategy.

Notice that the threshold of condition (9) is higher than the thresholds of conditions (7) and (8). However, the relationship between the threshold costs of conditions (7) and (8) depends on the incumbent's effective effort when $s_{I, 1}=e_{I, 2}=1$. In that case, equation (4) becomes $(\gamma+1)^{1 / \rho}$ and this effective effort can be interpreted as the incumbent's return of exerting high effort twice. When this return is low enough, $(\gamma+1)^{1 / \rho} \leq 2 \gamma^{1 / \rho}+1$, the condition (8) threshold is larger than condition ( 7$)$ threshold, $\frac{(\gamma+1)^{1 / \rho}-\gamma^{1 / \rho}}{\left[(\gamma+1)^{1 / \rho}+1\right]\left(\gamma^{1 / \rho}+1\right)} \leq \frac{1}{(\gamma+1)^{1 / \rho}+1}$ and the expected utilities from Table 2.1 imply the following behaviour strategies, 


$$
\left\{e_{I, 2}, e_{O, 2}\right\}=\left\{\begin{array}{ll}
\{1,1\} & \text { if } 0<c<\frac{(\gamma+1)^{1 / \rho}-\gamma^{1 / \rho}}{\left(\gamma^{1 / \rho}+1\right)\left[(\gamma+1)^{1 / \rho}+1\right]} \\
\left\{r_{I, 2}, 1\right\} & \text { if } c=\frac{(\gamma+1)^{1 / \rho}-\gamma^{1 / \rho}}{\left(\gamma^{1 / \rho}+1\right)\left[(\gamma+1)^{1 / \rho}+1\right]}, \text { where } r_{I, 2} \in[0,1] \\
\{0,1\} & \text { if } \frac{(\gamma+1)^{1 / \rho}-\gamma^{1 / \rho}}{\left(\gamma^{1 / \rho}+1\right)\left[(\gamma+1)^{1 / \rho}+1\right]}<c<\frac{1}{\gamma^{1 / \rho}+1} \\
\left\{0, q_{O, 2}\right\} & \text { if } c=\frac{1}{\gamma^{1 / \rho}+1}, \text { where } q_{O, 2} \in[0,1] \\
\{0,0\} & \text { if } \frac{1}{\gamma^{1 / \rho}+1}<c<\frac{1}{2}
\end{array},\right.
$$

where $r_{I, 2}\left(q_{O, 2}\right)$ is the probability that agent I $(\mathrm{O})$ exerts high effort in contest 2 .

When the incumbent's return of exerting high effort twice is high enough, $(\gamma+1)^{1 / \rho}>2 \gamma^{1 / \rho}+$ 1 , the condition (8) threshold is lower than the condition (7) threshold, $\frac{(\gamma+1)^{1 / \rho}-\gamma^{1 / \rho}}{\left[(\gamma+1)^{1 / \rho}+1\right]\left(\gamma^{1 / \rho}+1\right)}>$ $\frac{1}{(\gamma+1)^{1 / \rho}+1}$ and the expected utilities from Table 2.1 imply the following behaviour strategies,

$$
\left\{r_{I, 2}, q_{O, 2}\right\}= \begin{cases}\{1,1\} & \text { if } 0<c<\frac{1}{(\gamma+1)^{1 / \rho}+1} \\ \left\{1, q_{O, 2}\right\} & \text { if } c=\frac{1}{(\gamma+1)^{1 / \rho}+1}, \text { where } q_{O, 2} \in\left[\bar{q}_{O, 2}, 1\right] \\ \left\{\bar{r}_{I, 2}, \bar{q}_{O, 2}\right\} & \text { if } \frac{1}{(\gamma+1)^{1 / \rho}+1}<c<\frac{(\gamma+1)^{1 / \rho}-\gamma^{1 / \rho}}{\left(\gamma^{1 / \rho}+1\right)\left[(\gamma+1)^{1 / \rho}+1\right]} \text { where } \\ \left\{r_{I, 2}, 1\right\} & \left(\bar{r}_{I, 2}, \bar{q}_{O, 2}\right)=\left(\frac{(\gamma+1)^{1 / \rho}+1}{(\gamma+1)^{1 / \rho}-\gamma^{1 / \rho}}-\bar{q}_{O, 2}, c \frac{\left(\gamma^{1 / \rho}+1\right)\left[(\gamma+1)^{1 / \rho}+1\right]}{(\gamma+1)^{1 / \rho}-\gamma^{1 / \rho}}\right) . \\ \{0,1\} & \text { if } c=\frac{(\gamma+1)^{1 / \rho}-\gamma^{1 / \rho}}{\left(\gamma^{1 / \rho}+1\right)\left[(\gamma+1)^{1 / \rho}+1\right]}, \text { where } r_{I, 2} \in\left[0, \bar{r}_{I, 2}\right] \\ \left\{0, q_{O, 2}\right\} & \text { if } \frac{(\gamma+1)^{1 / \rho}-\gamma^{1 / \rho}}{\left(\gamma^{1 / \rho}+1\right)\left[(\gamma+1)^{1 / \rho}+1\right]}<c<\frac{1}{\gamma^{1 / \rho}+1} \\ \{0,0\} & \text { if } c=\frac{1}{\gamma^{1 / \rho}+1}, \text { where } q_{O, 2} \in[0,1]\end{cases}
$$

Notice that when $\frac{1}{(\gamma+1)^{1 / \rho}+1}<c<\frac{(\gamma+1)^{1 / \rho}-\gamma^{1 / \rho}}{\left(\gamma^{1 / \rho}+1\right)\left[(\gamma+1)^{1 / \rho}+1\right]}$, no agent has a dominant strategy and both agents play mixed strategies.

At service 1, the incumbent chooses the service effort. If he exerts costly high effort, he obtains 1 monetary unit and his expected utility at contest 2 ,

$$
E U_{I, 1}\left(s_{I, 1}=1\right)=1-c+E U_{I, 2}\left(\left(r_{I, 2}, q_{O, 2}\right) \mid s_{I, 1}=1\right) .
$$

On the contrary, if the incumbent chooses shirking at service 1 , he obtains 1 monetary unit and his expected utility at contest 2 ,

$$
E U_{I, 1}\left(s_{I, 1}=0\right)=1+E U_{I, 2}\left((1,1) \mid s_{I, 1}=0\right)=3 / 2-c .
$$

Given the incumbent's expected utility and agents' behaviour strategies at contest 2, at 
service 1 the incumbent balance the service effort cost and his probability of winning contest 2 . Firstly, consider that the incumbent's return of exerting high effort twice is low, $(\gamma+1)^{1 / \rho} \leq$ $2 \gamma^{1 / \rho}+1$. The incumbent's behaviour strategy in service 1 and the obtained SPE can be described by the sequence of efforts on the path $\left\{\left(s_{I, 1}\right),\left(e_{I, 2}, e_{O, 2}\right)\right\}$ when $\gamma<1$,

$$
\begin{cases}\{(1),(1,1)\} & \text { if } 0<c<\frac{(\gamma+1)^{1 / \rho}}{(\gamma+1)^{1 / \rho}+1}-\frac{1}{2} \\ \left\{\left(x_{I, 1}\right),(1,1)\right\} & \text { if } c=\frac{(\gamma+1)^{1 / \rho}}{(\gamma+1)^{1 / \rho}+1}-\frac{1}{2}, \text { where } x_{I, 1} \in[0,1] \\ \{(0),(1,1)\} & \text { if } \frac{(\gamma+1)^{1 / \rho}}{(\gamma+1)^{1 / \rho}+1}-\frac{1}{2}<c<\frac{1}{2}\end{cases}
$$

where $x_{I, 1}$ is the probability that the incumbent exerts high effort in service 1 . When $\gamma=1$, the incumbent's behaviour strategy in service 1 and the obtained SPE through the sequence of efforts on the path are described below,

$$
\begin{cases}\{(1),(1,1)\} & \text { if } 0<c<\frac{2^{1 / \rho}-1}{2\left[2^{1 / \rho}+1\right]} \\ \left\{\left(x_{I, 1}\right),\left(r_{I, 2}, 1\right)\right\} & \text { if } c=\frac{2^{1 / \rho}-1}{2\left[2^{1 / \rho}+1\right]}, \text { where } x_{I, 1} \in[0,1],\left\{r_{I, 2} \mid s_{I, 1}=0\right\}=1 \\ & \text { and }\left\{r_{I, 2} \mid s_{I, 1}=1\right\} \in[0,1] \\ \left\{\left(x_{I, 1}\right),\left(r_{I, 2}, 1\right)\right\} & \text { if } \frac{2^{1 / \rho}-1}{2\left[2^{1 / \rho}+1\right]}<c<\frac{1}{2}, \text { where } x_{I, 1} \in[0,1],\left\{r_{I, 2} \mid s_{I, 1}=0\right\}=1 \\ & \text { and }\left\{r_{I, 2} \mid s_{I, 1}=1\right\}=0\end{cases}
$$

When $\gamma>1$, the incumbent always exerts high service effort for any $c<1 / 2$. The obtained SPE are described by the sequence of efforts on the path,

$$
\left\{\begin{array}{ll}
\{(1),(1,1)\} & \text { if } 0<c<\frac{(\gamma+1)^{1 / \rho}-\gamma^{1 / \rho}}{\left(\gamma^{1 / \rho}+1\right)\left[(\gamma+1)^{1 / \rho}+1\right]} \\
\left\{(1),\left(r_{I, 2}, 1\right)\right\} & \text { if } c=\frac{(\gamma+1)^{1 / \rho}-\gamma^{1 / \rho}}{\left(\gamma^{1 / \rho}+1\right)\left[(\gamma+1)^{1 / \rho}+1\right]}, \text { where } r_{I, 2} \in[0,1] \\
\{(1),(0,1)\} & \text { if } \frac{(\gamma+1)^{1 / \rho}-\gamma^{1 / \rho}}{\left(\gamma^{1 / \rho}+1\right)\left[(\gamma+1)^{1 / \rho}+1\right]}<c<\frac{1}{\gamma^{1 / \rho}+1} \\
\left\{(1),\left(0, q_{O, 2}\right)\right\} & \text { if } c=\frac{1}{\gamma^{1 / \rho}+1}, \text { where } q_{O, 2} \in[0,1] \\
\{(1),(0,0)\} & \text { if } \frac{1}{\gamma^{1 / \rho}+1}<c<\frac{1}{2}
\end{array} .\right.
$$

Consider now that the incumbent's return of exerting high effort twice is high, $(\gamma+1)^{1 / \rho}>$ $2 \gamma^{1 / \rho}+1$. When $\gamma<1$, the incumbent's behaviour strategy in service 1 and the obtained SPE 
are described by the following sequence of efforts on the path, ${ }^{34}$

$$
\left\{\begin{array}{ll}
\{(1),(1,1)\} & \text { if } 0<c<\min \left\{\frac{(\gamma+1)^{1 / \rho}}{(\gamma+1)^{1 / \rho}+1}-\frac{1}{2}, \frac{1}{(\gamma+1)^{1 / \rho}+1}\right\} \\
\left\{\left(x_{I, 1}\right),(1,1)\right\} & \text { if } c=\frac{(\gamma+1)^{1 / \rho}}{(\gamma+1)^{1 / \rho}+1}-\frac{1}{2}, \text { where } x_{I, 1} \in[0,1] \\
\left\{\left(x_{I, 1}\right),\left(1, q_{O, 2}\right)\right\} & \text { if } c=\frac{1}{(\gamma+1)^{1 / \rho}+1}, \text { where } x_{I, 1} \in[0,1],\left\{q_{O, 2} \mid s_{I, 1}=0\right\}=1 \\
\left\{(1),\left(\bar{r}_{I, 2}, \bar{q}_{O, 2}\right)\right\} & \text { and }\left\{q_{O, 2} \mid s_{I, 1}=1\right\} \in\left[\bar{q}_{O, 2}, 1\right] \\
\left\{\left(x_{I, 1}\right),\left(r_{I, 2}, q_{O, 2}\right)\right\} & \text { if } \frac{1}{(\gamma+1)^{1 / \rho}+1}<c<\frac{(\gamma+1)^{1 / \rho}-\gamma^{1 / \rho}}{2\left[(\gamma+1)^{1 / \rho}+1\right]} \\
& \text { if } c=\frac{(\gamma+1)^{1 / \rho}-\gamma^{1 / \rho}}{2\left[(\gamma+1)^{1 / \rho}+1\right]}, \text { where } x_{I, 1} \in[0,1],\left(\left(r_{I, 2}, q_{O, 2}\right) \mid s_{I, 1}=0\right)=(1,1) \\
\{(0),(1,1)\} & \text { and }\left(\left(r_{I, 2}, q_{O, 2}\right) \mid s_{I, 1}=1\right)=\left(\bar{r}_{I, 2}, \bar{q}_{O, 2}\right) \\
& \text { if } \frac{(\gamma+1)^{1 / \rho}}{(\gamma+1)^{1 / \rho}+1}-\frac{1}{2}<c<\frac{1}{(\gamma+1)^{1 / \rho}+1} \text { and } / \text { or } \\
& \max \left\{\frac{1}{(\gamma+1)^{1 / \rho}+1}, \frac{(\gamma+1)^{1 / \rho}-\gamma^{1 / \rho}}{2\left[(\gamma+1)^{1 / \rho}+1\right]}<c<\frac{1}{2}\right.
\end{array} .\right.
$$

When $\gamma=1$, the incumbent's behaviour strategy in service 1 and the obtained SPE through the sequence of efforts on the path are described below,

$$
\begin{cases}\{(1),(1,1)\} & \text { if } 0<c<\frac{1}{2^{1 / \rho}+1} \\ \left\{(1),\left(1, q_{O, 2}\right)\right\} & \text { if } c=\frac{1}{2^{1 / \rho}+1}, \text { where }\left\{q_{O, 2} \mid s_{I, 1}=1\right\} \in\left[\bar{q}_{O, 2}, 1\right] \\ \left\{(1),\left(\bar{r}_{I, 2}, \bar{q}_{O, 2}\right)\right\} & \text { if } \frac{1}{2^{1 / \rho}+1}<c<\frac{2^{1 / \rho}-1}{2\left(2^{1 / \rho}+1\right)} \\ \left\{\left(x_{I, 1}\right),\left(r_{I, 2}, 1\right)\right\} & \text { if } c=\frac{2^{1 / \rho}-1}{2\left(2^{1 / \rho}+1\right)}, \text { where } x_{I, 1} \in[0,1],\left\{r_{I, 2} \mid s_{I, 1}=0\right\}=1 \\ & \text { and }\left\{r_{I, 2} \mid s_{I, 1}=1\right\} \in\left[0, \bar{r}_{I, 2}\right] \\ \left\{\left(x_{I, 1}\right),\left(r_{I, 2}, 1\right)\right\} & \text { if } \frac{2^{1 / \rho}-1}{2\left(2^{1 / \rho}+1\right)}<c<\frac{1}{2} \text { where } x_{I, 1} \in[0,1],\left\{r_{I, 2} \mid s_{I, 1}=0\right\}=1 \\ & \text { and }\left\{r_{I, 2} \mid s_{I, 1}=1\right\}=0\end{cases}
$$

When $\gamma>1$, the incumbent always exert high effort in providing service 1 for any $c<1 / 2$. The

\footnotetext{
${ }^{34}$ Notice that when $c=\frac{1}{(\gamma+1)^{1 / \rho}+1}$ and $\gamma<1$, the incumbent shirks (does not shirk) in providing service 1 if he thinks it is likely that his opponent will exert high (low) effort at contest 2 ,

$$
\left\{\begin{array}{ll}
s_{I, 1}=1 & \text { if } q_{O, 2}<\frac{(\gamma+1)^{1 / \rho}-1}{2} \\
x_{I, 1} \in[0,1] & \text { if } q_{O, 2}=\frac{(\gamma+1)^{1 / \rho}-1}{2 / \rho} \\
s_{I, 1}=0 & \text { if } q_{O, 2}>\frac{(\gamma+1)^{1 / \rho}}{2}
\end{array} .\right.
$$
}


obtained SPE are described by the following sequence of efforts on the path,

$$
\begin{cases}\{(1),(1,1)\} & \text { if } 0<c<\frac{1}{(\gamma+1)^{1 / \rho}+1} \\ \left\{(1),\left(1, q_{O, 2}\right)\right\} & \text { if } c=\frac{1}{(\gamma+1)^{1 / \rho}+1}, \text { where } q_{O, 2} \in\left[\bar{q}_{O, 2}, 1\right] \\ \left\{(1),\left(\bar{r}_{I, 2}, \bar{q}_{O, 2}\right)\right\} & \text { if } \frac{1}{(\gamma+1)^{1 / \rho}+1}<c<\frac{(\gamma+1)^{1 / \rho}-\gamma^{1 / \rho}}{\left(\gamma^{1 / \rho}+1\right)\left[(\gamma+1)^{1 / \rho}+1\right]} \\ \left\{(1),\left(r_{I, 2}, 1\right)\right\} & \text { if } c=\frac{(\gamma+1)^{1 / \rho}-\gamma^{1 / \rho}}{\left(\gamma^{1 / \rho}+1\right)\left[(\gamma+1)^{1 / \rho}+1\right]}, \text { where } r_{I, 2} \in\left[0, \bar{r}_{I, 2}\right] . \\ \{(1),(0,1)\} & \text { if } \frac{(\gamma+1)^{1 / \rho}-\gamma^{1 / \rho}}{\left(\gamma^{1 / \rho}+1\right)\left[(\gamma+1)^{1 / \rho}+1\right]}<c<\frac{1}{\gamma^{1 / \rho}+1} \\ \left\{(1),\left(0, q_{O, 2}\right)\right\} & \text { if } c=\frac{1}{\gamma^{1 / \rho}+1}, \text { where } q_{O, 2} \in[0,1] \\ \{(1),(0,0)\} & \text { if } \frac{1}{\gamma^{1 / \rho}+1}<c<\frac{1}{2}\end{cases}
$$

\subsection{Proof of Proposition 3: $\gamma \rightarrow \infty$ and $0<\rho \leq 1$}

At contest 2, the incumbent's effective effort from equation (4) depends on his effort in providing service 1 . On the one hand, if the incumbent shirked at service $1\left(s_{I, 1}=0\right)$, his effective effort is his current effort $e_{I, 2}$. Then, from Lemma 1, we know that both agents exert high effort at contest 2 when $c<1 / 2$ and $E U_{I, 2}\left((1,1) \mid s_{I, 1}=0\right)=1 / 2-c$. On the other hand, if the incumbent did not shirk in providing service $1\left(s_{I, 1}=1\right)$, his effective effort from equation (4) tends to $\left(\infty+e_{I, 2}^{\rho}\right)^{1 / \rho}=\infty$. Table A.3 shows the agents' expected utility at contest 2 for each combination of contest effort when $s_{I, 2}=1$.

\begin{tabular}{|c|c|c|}
\cline { 2 - 3 } \multicolumn{1}{c|}{} & $e_{O, 2}=0$ & $e_{O, 2}=1$ \\
\hline$e_{I, 2}=0$ & 1,0 & $\frac{\infty}{\infty+1}, \frac{1}{\infty+1}-c$ \\
\hline$e_{I, 2}=1$ & $1-c, 0$ & $\frac{\infty}{\infty+1}-c, \frac{1}{\infty+1}-c$ \\
\hline
\end{tabular}

Table A.3. Agents' expected utilities at contest 2 when $s_{I, 2}=1$ for $\gamma \rightarrow \infty, 0<\rho \leq 1\left(E U_{I, 2}\right.$ on the left and $E U_{O, 2}$ on the right).

Notice that the incumbent's dominant strategy is exerting high effort $\left(e_{I, 2}=1\right)$ while the opponent's dominant strategy is exerting low effort $\left(e_{O, 2}=0\right)$. Therefore, if the incumbent did not shirk in providing service 1, his expected utility at contest 2 is $E U_{I, 2}\left((1,0) \mid s_{I, 1}=1\right)=1$.

At service 1, the incumbent's expected utility is higher when he exerts high service effort,

$$
E U_{I, 1}(0)=1+\frac{1}{2}-c<1-c+1=E U_{I, 1}(1)
$$

Therefore, the incumbent never shirks in providing service 1 for any $c<1 / 2$. The obtained 
SPE can be described by the sequence of efforts on the path $\left\{\left(s_{I, 1}\right),\left(e_{I, 2}, e_{O, 2}\right)\right\}$ when $\gamma \rightarrow \infty$,

$$
\left\{\{(1),(0,0)\} \quad \text { if } c<\frac{1}{2} .\right.
$$

\subsection{Proof of Proposition 4: $\gamma>0$ and $\rho \rightarrow 0$}

At contest 2, the incumbent's effective effort from equation (5) depends on his current effort and on service 1 effort. On the one hand, if the incumbent shirked at service $1\left(s_{I, 1}=0\right)$, his effective effort is equal to zero even if he exerts high effort at contest 2 . Table A.4 summarizes the expected utility of both agents, $E U_{I, 2}\left(\left(e_{I, 2}, e_{O, 1}\right) \mid s_{I, 1}=0\right)$ on the left and $E U_{O, 2}\left(\left(e_{I, 2}, e_{O, 1}\right) \mid s_{I, 1}=0\right)$ on the right, for any combination of agents' binary effort.

$$
\begin{array}{|c|c|c|}
\cline { 2 - 3 } \multicolumn{1}{c|}{} & e_{O, 2}=0 & e_{O, 2}=1 \\
\hline e_{I, 2}=0 & \frac{1}{2}, \frac{1}{2} & 0,1-c \\
\hline e_{I, 2}=1 & \frac{1}{2}-c, \frac{1}{2} & -c, 1-c \\
\hline
\end{array}
$$

Table A.4. Agents' expected utilities at contest 2 when $s_{I, 2}=0$ for $\gamma>0, \rho \rightarrow 0\left(E U_{I, 2}\right.$ on the left and $E U_{O, 2}$ on the right).

Notice that the incumbent's dominant strategy is exerting low effort while the opponent's dominant strategy is exerting high effort. Therefore, if the incumbent exerted low effort in service 1, his expected utility in contest 2 is $E U_{I, 2}\left((0,1) \mid s_{I, 1}=0\right)=0$.

On the other hand, if the incumbent did not shirk at service $1\left(s_{I, 1}=1\right)$, his effective effort from equation (5) is equal to his current effort $e_{I, 2}$. Table A.5 shows the agents' expected utility at contest 2 for each combination of agents' binary effort when $s_{I, 2}=1$.

$$
\begin{array}{|c|c|c|}
\cline { 2 - 3 } \multicolumn{1}{c|}{} & e_{O, 2}=0 & e_{O, 2}=1 \\
\hline e_{I, 2}=0 & \frac{1}{2}, \frac{1}{2} & 0,1-c \\
\hline e_{I, 2}=1 & 1-c, 0 & \frac{1}{2}-c, \frac{1}{2}-c \\
\hline
\end{array}
$$

Table A.5. Agents' expected utilities at contest 2 when $s_{I, 2}=1$ for $\gamma>0, \rho \rightarrow 0\left(E U_{I, 2}\right.$ on the left and $E U_{O, 2}$ on the right).

Notice that both agents have the same dominant strategy at contest 2 when $s_{I, 1}=1$ : high effort for any $c<1 / 2$. Therefore, if the incumbent exerted high effort at service 1 , his expected utility at contest 2 is $E U_{I, 2}\left((1,1) \mid s_{I, 1}=1\right)=1 / 2-c$.

At service 1, the incumbent chooses service 1 effort. Equations (21) and (22) are the incum- 
bent's expected utilities of exerting low and high service effort at service 1, respectively.

$$
\begin{gathered}
E U_{I, 1}(0)=1 \\
E U_{I, 1}(1)=1-c+\frac{1}{2}-c
\end{gathered}
$$

When effort is relatively cheap, $c<1 / 4$, the incumbent chooses exerting high service effort. However, for more expensive efforts, he shirks. The incumbent's behaviour strategy in service 1 and the obtained SPE can be described by the sequence of efforts on the path $\left\{\left(s_{I, 1}\right),\left(e_{I, 2}, e_{O, 2}\right)\right\}$ when $\rho \rightarrow 0$,

$$
\begin{cases}\{(1),(1,1)\} & \text { if } 0<c<\frac{1}{4} \\ \left\{\left(x_{I, 1}\right),\left(r_{I, 2}, 1\right)\right\} & \text { if } c=\frac{1}{4}, \text { where } x_{I, 1} \in[0,1] \text { and } r_{I, 2} \in[0,1] \\ \{(0),(0,1)\} & \text { if } \frac{1}{4}<c<\frac{1}{2}\end{cases}
$$

where $x_{I, 1}\left(r_{I, 2}\right)$ is the probability that the incumbent exerts high effort in service 1 (contest 2).

\section{References}

Audet, D., 2002. Government Procurement: A synthesis report. OECD Journal on Budgeting 2(3), $149-194$.

Beviá, C., Corchón, L., 2013. Endogenous Strength in Conflicts. International Journal of Industrial Organization 31(3), $297-306$.

Bolton, P., Dewatripont, M., 2005. Contract Theory. Massachussets Institute of Technology; Cambridge.

Cesi, B., Albano, G.L., 2008. Past Performance Evaluation in Repeated Procurement: A Simple Model of Handicapping. 3rd International Public Procurement Conference Proceedings, 875 $-898$.

Che, Y.K., Gale, I., 2003. Optimal Design of Research Contests. American Economic Review $93(3), 646-671$.

Chiappori, P.A., Macho, I., Rey, P., Salanié, B., 1994. Repeated Moral Hazard: The Role of 
Memory, Commitment, and the Access to Credit Markets. European Economic Review 38, $1527-1553$.

Clark, D.J., Nilssen, T., 2013. Learning by Doing in Contests. Public Choice 156, 329 - 343.

Clark, D.J., Riis, C., 1998. Contest Success Functions: An Extension. Economic Theory 11(1), $201-204$.

Corchón, L., Dahm, M., 2010. Foundations for Contest Success Functions. Economic Theory $43(1), 81-98$.

Corchón, L., Dahm, M., 2011. Welfare Maximizing Contest Success Functions when the Planner Cannot Commit. Journal of Mathematical Economics 47(3), 309 - 317.

Dahm, M., Porteiro N., 2008. Biased Contests. Public Choice 136(1-2), 55 - 67.

Epstein, G.S., Mealem, Y., Nitzan, S., 2011. Political Culture and Discrimination in Contests. Journal of Public Economics 95, 88 - 93.

European Commission, 2011. Public Procurement in Europe: costs and effectiveness. Study published online at http://ec.europa.eu/internal_market/publicprocurement

Fu, Q., Lu, J., 2009. Contest with Pre-contest Investment. Economics Letters 103, 142 - 145.

Fullerton, R.L., McAfee, R.P., 1999. Auctioning Entry into Tournaments. Journal of Political Economy 107(3), $573-605$.

Gibbons, R., Waldman, M., 1999. Careers in Organizations: Theory and Evidence. In: Ashenfelter, O., Card, D., (Editors). Handbook of Labor Economics, Volume 3; Elsevier Science B.V.

Gürtler, O., Kräkel, M., 2010. Double-Sided Moral Hazard, Efficiency Wages, and Litigation. Journal of Law, Economics, and Organization 26(2), 337 - 364.

Holmström, B., 1979. Moral Hazard and Observability. Bell Journal of Economics 10(1), 74 91.

Iossa, E., Rey, P., 2014. Building Reputation for Contract Renewal: Implications for Performance Dynamics and Contract Duration. Journal of the European Economic Association $12(3), 549-574$. 
Jofre-Bonet, M., Pesendorfer, M., 2000. Bidding Behaviour in a Repeated Procurement Auction: A Summary. European Economic Review 44(4-6), 1006 - 1020.

Konrad, K.A., 2002. Investment in the Absence of Property Rights; the Role of Incumbency Advantages. European Economic Review 46, 1521 - 1537.

Konrad, K.A., 2009. Strategy and Dynamics in Contests. Oxford University Press Inc.; New York.

Kovenock, D., Roberson, B., 2009. Is the 50-State Strategy Optimal? Journal of Theoretical Politics 21(2), $213-236$.

Laffont, JJ., Martimort, D., 2002. The Theory of Incentives: The Principal-Agent Model. Princeton University Press; Princeton, NJ.

Laffont, JJ., Tirole, J.A., 1999. Theory of Incentives in Procurement and Regulation. Massachussets Institute of Technology; Cambridge.

Lazear, E.P., Rosen, S., 1981. Rank-Order Tournaments as Optimum Labor Contracts. Journal of Political Economy 89(5), $841-864$.

Melkonyan, T., 2013. Hybrid Contests. Journal of Public Economic Theory 15(6), 968 - 992.

Meyer, M., 1992. Biased Contests and Moral Hazard: Implications for Career Profiles. Annals of Economics and Statistics 25/26, $165-187$.

Miller, G.J., 2005. The Political Evolution of Principal-Agent Models. Annual Review of Political Science 8, $203-225$.

Moldovanu, B., Sela, A., Shi, X., 2012. Carrots and Sticks: Prizes and Punishments in Contests. Economic Inquiry 50(2), $1453-462$.

Möller, M., 2012. Incentives versus Competitive Balance. Economics Letters 117(2), 505 - 508.

Münster, J., 2007. Contests with Investment. Managerial and Decision Economics 28, 849 862.

Ohlendorf, S., Schmitz, P.W., 2012. Repeated Moral Hazard and Contracts with Memory: The Case of Risk-neutrality. International Economic Review 53(2), 433 - 452.

Persson, T., Roland, G., Tabellini, G., 1997. Separation of Powers and Political Accountability. The Quarterly Journal of Economics 112, 1163 - 1202. 
Ridlon, R., Shin, J., 2013. Favoring the Winner or Loser in Repeated Contests. Marketing Science 32(5), $768-785$.

Siegel, R., 2010. Asymmetric Contests with Conditional Investments. American Economic Review 100(5), $2230-2260$.

Skaperdas, S., 1996. Contest Success Functions. Economic Theory 7(2), $283-290$.

Spagnolo, G., 2012. Reputation, Competition, and Entry in Procurement. International Journal of Industrial Organization 30, 291-296.

Taylor, C.R., 1995. Digging for Golden Carrots: An Analysis of Research Tournaments. American Economic Review 85(4), 872 - 890.

Tullock, G., 1980. Efficient Rent Seeking. In Buchanan J., Tollison R., Tullock G. (editors). Toward a theory of the rent-seeking society. College Station; Texas A \& M University Press.

US Government Spending, 2014. Prime Award Spending Data. Retrieved in November from http://www.usaspending.gov/

Varian, H.R., 1992. Microeconomic Analysis, Third Edition. W.W. Norton \& Company, Inc.; New York.

World Bank, 2016. World Development Indicators. Retrieved in January from http://data.worldbank.org/ 


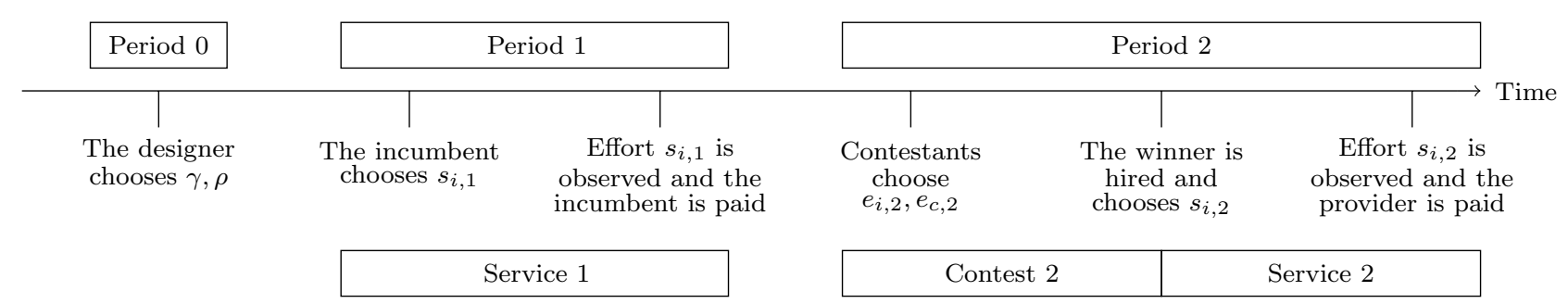

Figure 1: Timing of the model. At $t=0$, the designer chooses the setting of contest 2 (the biased contest) by choosing $\gamma$ and $\rho$. At period 1, there is a service stage in which the incumbent provides a service. At period 2, there are two stages: a contest stage in which a new service provider can be selected, and a service stage.

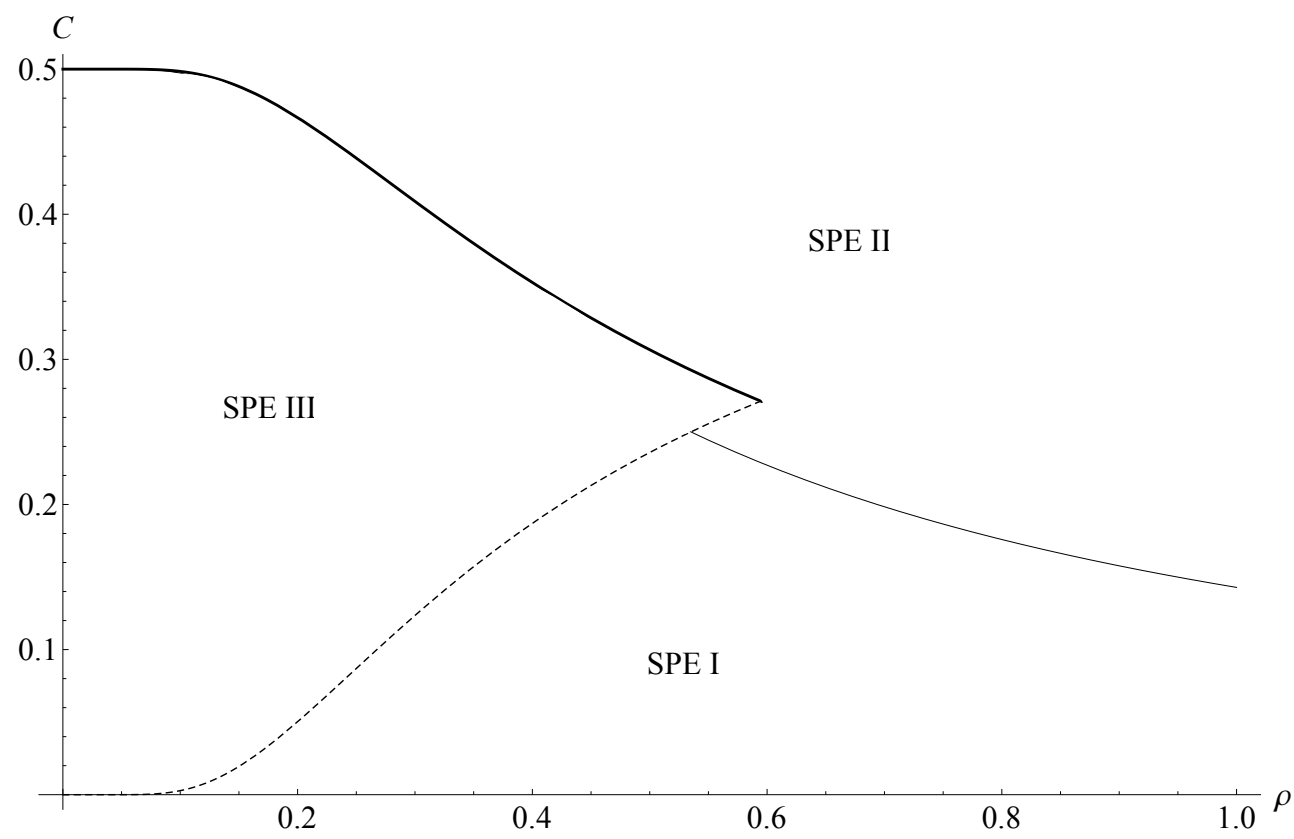

Figure 2: Relationship between SPE, $\rho$ and effort cost when $\gamma=0.8$. In SPE I, moral hazard is mitigated and contest effort is maximum. In SPE II, moral hazard cannot be avoided and contests effort is maximum. In SPE III, moral hazard is mitigated and contest 2 effort is not maximum. 


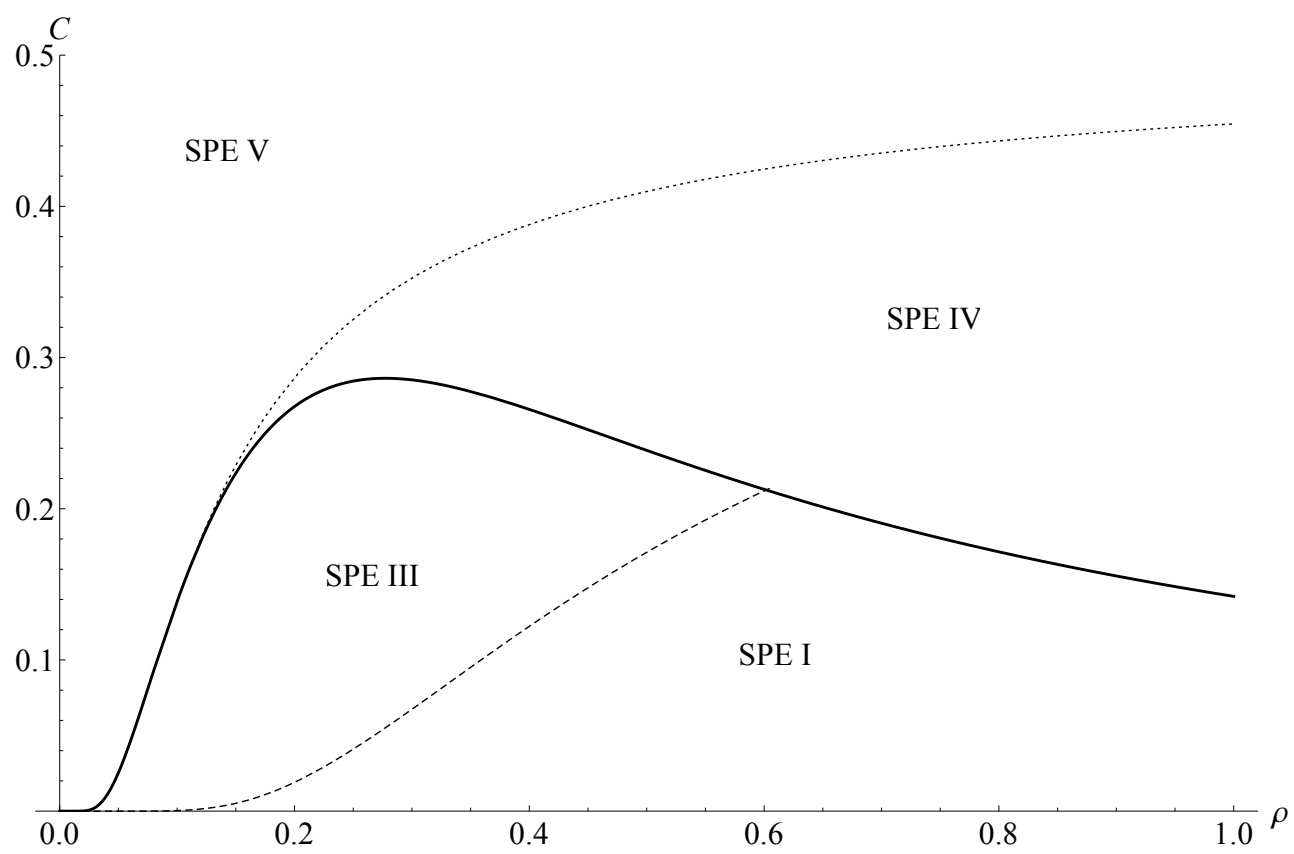

Figure 3: Relationship between SPE, $\rho$ and effort cost when $\gamma=1.2$. In SPE I, moral hazard is mitigated and contest effort is maximum. In SPE III and IV, moral hazard is mitigated and contest 2 effort is not maximum (expected contest effort is higher in SPE III than in SPE IV). In SPE V, moral hazard is mitigated and contest 2 effort is minimum.

\begin{tabular}{lccc} 
& Total service effort & Total contest effort & Total effort \\
\hline SPE I & 1 & 2 & 3 \\
SPE II & 0 & 2 & 2 \\
SPE III & 1 & $\frac{1+(\gamma+1)^{1 / \rho}}{(\gamma+1)^{1 / \rho}-\gamma^{1 / \rho}}$ & $1+\frac{1+(\gamma+1)^{1 / \rho}}{(\gamma+1)^{1 / \rho}-\gamma^{1 / \rho}}$ \\
SPE IV & 1 & 1 & 2 \\
SPE V & 1 & 0 & 1 \\
SPE VI & 0 & 1 & 1 \\
\hline
\end{tabular}

Table 1: Total contest and service efforts for the SPE obtained in Propositions 1, 2, 3 and 4. Notice that total contest effort in SPE III is larger than 1 and smaller than 2. Therefore, the sum of service and contest efforts is larger than 2 but smaller than 3 in SPE III. 


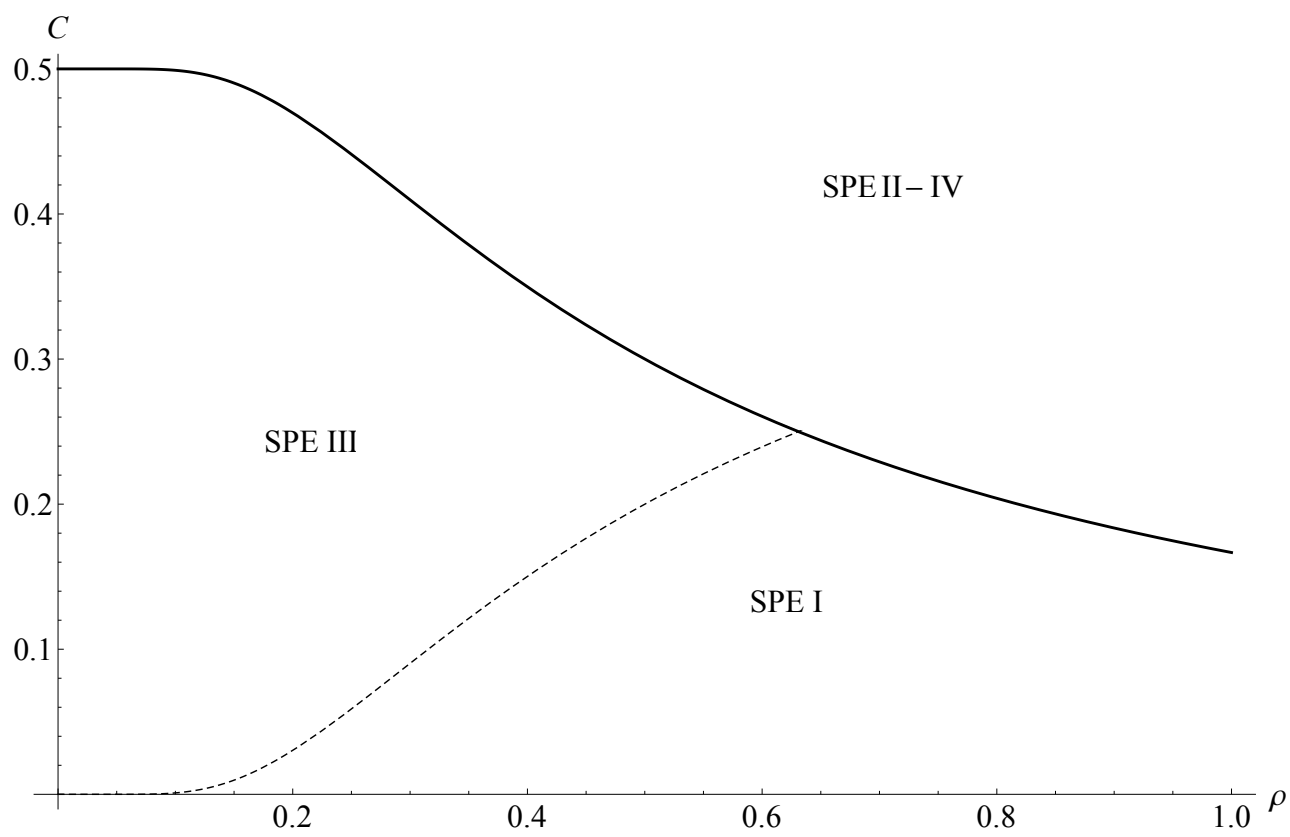

Figure 4: Relationship between SPE, $\rho$ and effort cost when $\gamma=1$. In SPE I, moral hazard is mitigated and contest effort is maximum. In SPE II, moral hazard cannot be avoided and contests effort is maximum. In SPE III and IV, moral hazard is mitigated and contest 2 effort is not maximum (expected contest effort is higher in SPE III than in SPE IV). 